\title{
Rights and Power: The Challenge for International Development Agencies
}

\author{
Alexandra Hughes, Joanna Wheeler and Rosalind Eyben*
}

\section{Introduction}

Rights-based approaches are increasingly part of the policy and practice of international development agencies. But how can these agencies support people's own efforts to turn rights into reality? While some believe these new approaches offer the potential for a fundamental and positive change for international development agency relations with governments and civil society in aid recipient countries, others remain puzzled or sceptical as to their relevance for achieving the Millennium Development Goals. Some observers suspect that agencies have appropriated the "rights" language without changing the way they go about their business.

What is clear is that rights-based approaches are challenging. They reveal difficult issues concerning the legitimacy of action, the practice of power and lines of accountability. As argued in the introduction to this IDS Bulletin, rights have the potential to raise important challenges to existing power structures and can lead to significant change. However, for rights in development to be able to be a catalyst for change, rather than a top-down bureaucratic exercise, an understanding of how power and rights are interlinked is essential.

Exploring power and power relations is a critical challenge facing those trying to support rights in practice, as a recent workshop at the Institute of Development Studies for the staff of a range of international development agencies demonstrated. Many of the power structures development actors face, such as the international economic regime, are very difficult to change. However, there is a need to recognise and understand the dynamics of power in the context of day-to-day experience and the positive ways in which individuals within development agencies can use their own power, whatever its limitations. Power is both an obstacle to rights-based approaches to development and a tool that can be used to support struggles for claiming and realising rights.

The premise of the workshop was that it is necessary to understand ourselves as actors engaged in the dynamics of relationships of power in order to be able to understand and promote the realisation of rights. This approach to power, as understood through the lens of personal experience, highlighted some of the deeply rooted obstacles to promoting rights in practice. Many of the participants' experiences revealed the ways in which work promoting rights is political, unexpected, often complex, confused and potentially emotionally demanding (Groves and Hinton 2004; Scott-Villiers 2004).

By approaching the issue of power and its implications for promoting rights in practice through experiential learning, the workshop aimed to link together a conceptualisation of power and rights-based approaches with the daily encounters with power for those involved in promoting rights. Experiential knowing is through face-to-face encounters; through empathy and resonance, as opposed to knowing about ideas or theories (Reason 1998). Experiential approaches to learning can be instrumental in deepening understanding and capacity for adaptation to complex development processes (Pasteur and Scott-Villiers 2004; Irvine, Chambers and Eyben 2004), because these approaches focus on how our own actions constitute our experiences (Reason 1998). Approaching power through experiential knowledge brought out some of the serious tensions and contradictions that emerge in trying to promote rights in development.

An approach to power, developed by French sociologists such as Callon and Latour (discussed in Clegg 1989) would suggest that as the international development agencies have already defined the 


\section{Box 1: Mr Big on Literacy in Surlandia}

Mr Inbetween, Surlandia's country officer for Donor Agency, has been working to build an alliance between a local NGO coalition, the Ministry of Education and the Church, in support of a critical literacy programme. After a year of negotiations, they have agreed to work together and Mr Big back in headquarters has virtually committed to fund the programme. Mr Inbetween rushes to a meeting, where the partners are anxiously waiting, to pass on the news that Mr Big is in favour of the programme. His good news is greeted with much enthusiasm and there is a fruitful planning session. Finally, the long year of partnership building and negotiation is going to pay off - Surlandia's literacy rate has a chance to improve!

A few weeks later, Mr Inbetween calls Mr Big again to convey local level enthusiasm and confirm the programme's approval. Mr Big has little time to chat. He says he was going to issue a memo that week some time and tells Mr Inbetween (rather coldly) that funds have been redirected to Iraq. The literacy programme will have to wait. Mr Big is late for an important meeting and hangs up. Inbetween is in shock. Gradually, his every pore is saturated with rage, disappointment and frustration. Too embarrassed to call himself, Inbetween asks Miss Secretary to call another meeting. His local partners sense something is wrong.

At the meeting and with nervous grunts in between words, Mr Inbetween explains that the project funding has been redirected. He is consumed by guilt and leaves the meeting hastily. He says he is late for another appointment. Left alone, the leaders sit around the table quietly for some moments. These things have been known to happen in Surlandia before. And surely they would happen again. What was difficult was that it was outsiders they had to rely on. Or did they? Didn't the coalition between church, government and civil society provide a strong enough platform from which to gather resources to take the programme forward, even if it was on a smaller scale? They complain and then laugh about Surlandia's predicament and begin a long chat about the challenges and potentials of their new endeavour.

Source: Hughes et al. (2003).

problem (poverty) and the solution (aid), necessarily their concern is for tools to support the problemsolving effort. From this perspective, power denies questions. Probing the concepts we use is thus a first step to challenging ourselves about the way we think. Examining how rights and power are linked is a way of probing further what Midgely (1996) calls the "philosophical plumbing" of the way we understand the world works and our role within that world. However, any such exploration obliges us to confront our own power and agency and this can be acutely uncomfortable (Scott-Villiers 2004). It is questionable as to whether most of us are prepared to do this unless forced into it by external pressure.

The next section draws out how understanding power, both experientially and conceptually, is essential to promoting rights-based approaches to development. This is followed by some examples drawn from the workshop of the types of circumstances that underscore what makes rights so challenging for international development organisations. We then conclude by summarising the key actions that participants identified as steps to meeting more effectively what has been elsewhere described as the challenge of aligning human rights principles with procedures and practices (Cornwall and Nyamu-Musembi, this issue).

\subsection{Power mediates the realisation of rights}

Power relationships, their dynamics and structures mediate the realisation of rights. These relationships determine who is included and who is excluded in claiming and realising their rights and in determining their own development. This mediation can be better understood with a conceptualisation of power that categorises it into different dimensions: visible power, which operates in observable ways in "open" public arenas; hidden power, which upholds existing power dynamics, such as who is included or excluded from decision making; and invisible or intangible power, which affects personal experiences of power, such as socially embedded norms and the internalisation of a sense of powerlessness (Gaventa 1980; Lukes 1974; VeneKlasen and Miller 2002). 
Building on this three-dimensional understanding of power, participants in the workshop identified and dramatically enacted expressions of different forms of power they had experienced in the international aid system (see Box 1).

This sketch emphasises how hidden and invisible power can work in the context of international development. Mr Big in the head office was able to undermine the tenuous coalition of civil society actors in Surlandia through an exercise of hidden decision-making power to withhold promised funding. However, those at the end of the donorrecipient power chain realised that they had the power to act even without the previously promised support of the development agency. In so doing, they realised what might be interpreted as invisible power, challenging a previous sense of powerlessness. This sketch also highlighted the powerlessness of $\mathrm{Mr}$ Inbetween, who was undermined by the power of Mr Big and not able to tap into the power of the civil society actors because of the pressures of the donor environment.

As the example shows, power is also linked to roles and personal relationships. It particularly highlights the importance of investing in capacity and partnerships, networks and relationships for and between local organisations; efforts that might work towards enabling such actors to organise and work with citizens to demand their rights. And, in so doing, to challenge existing relationships of dependency and power structures as was the case with the coalition supported in Surlandia.

To help link power to personal experience of inclusion and exclusion, participants assumed different roles, from ambassador to nanny, to enact at a "cocktail party" at the embassy of Norlandia in the country of Surlandia. During the exercise, participants situated themselves in relationship to a "power pot", depending on how much personal power they perceived they would exercise at the party in their respective roles. A pattern of concentric circles emerged surrounding the power pot, where those more distant from the power pot were also more distanced from each other and those close to the power pot were closer together. The powerless emerged as fragmented rather than unified, where those with more power were closely linked to one another.

At this "cocktail party", participants used drama to assess power as conceptualised in terms of alliance building and networks (Clegg 1989). This concept allows us to explore how those who are already powerful associate together as a means of maintaining and strengthening their collective and individual agency. Thus, for example, the recent enthusiasm for donor harmonisation of approaches and procedures can be interpreted through this conceptual lens as a means to exert greater power over the recipients because under the terms of a coordinated donor partnership with a recipient government room for other perspectives is crowded out (Gould and Ojanen 2003).

Reflecting on the cocktail party drama, participants tended to understand their own positional power in terms of the stereotypes surrounding those roles. For example, the participant acting the role of a country director of the World Bank was situated very close to the power pot. However, real experience contested this stereotype when a workshop participant from the World Bank argued that the World Bank is not necessarily a powerful actor and is often constrained by institutional rules and burdens.

In further reflection, participants considered how power has multiple sources. These include the control of resources (representatives of donor agencies, ministries and international financial institutions), position (ambassadors, representatives of political parties), as well as the personal confidence in the particular context of a cocktail party that certain roles could take for granted (international non-governmental organisation (NGO) representatives versus local NGO representatives).

The "cocktail party" exercise demonstrated how power is also situational and not necessarily associated with one's position in a social hierarchy. While certain roles were perceived as powerful at the party, the same people could have different identities and levels of power in other contexts. Whereas some were comfortable and confident in the environment of a cocktail party, leading to greater power (or a sense of such), others, such as local NGO representatives or opposition politicians could be equally confident and powerful in other situations.

John Gaventa highlighted four main characteristics providing a framework for the dimensions of power that emerged out of the cocktail drama:

- Power is dynamic: Each dimension of power (visible, invisible, etc.) is in constant change in its interrelationship. Changes in one dimension will alter others. 
- Power is contextual: Strategies for achieving power for those living in poverty in one context may work towards disempowerment in another sphere.

- Power is historical: Even if new institutional openings appear, historical actors' learnt behaviours and attitudes may be enacted within them.

- Power is relational: Those who are relatively powerless in one setting may be more powerful in others.

In mapping different dimensions of power, Gaventa proposed that we must position ourselves as individuals with our own personal power, recognising the role this plays in driving change, using our positions and identities as positive power to: build alliances and understandings across differences; foster genuine relationships rather than partnerships-ofconvenience; refuse to be complicit with discrimination; break away from conventions; and "share the problem". Positive personal power becomes critical in terms of identifying entry points for influence and change, and for overcoming barriers.

\section{What makes rights so challenging for international development organisations?}

The workshop identified three key challenges. There was the need to get to grips with concepts rather than just using rights-based approaches as another tool; recognising multiple lines of accountability and appreciating the relationship between power and what is considered "legitimate" knowledge.

\subsection{New ways of thinking}

Exploring the concepts and values that inform our thinking about rights is difficult for development agencies anxious to achieve real world outcomes without wasting scarce time on such questions. However, by deconstructing the concepts and by asking questions, rather than proposing solutions, we may find that the problem is not what we had first thought it to be and that therefore our response, and the tools we decide to use, may also be rather different. However, because the power of development agencies in defining what is both the problem and the solution for developing countries is quasi-hegemonic, it is almost impossible to conceive how things could be done differently.

At the workshop, Rosalind Eyben introduced thinking from complex systems approaches concerned with how government bureaucracies respond to convergent (bounded) and divergent (unbounded) problems (Chapman 2002). She suggested that non-linear thinking might enable participants to be more effective in playing a supportive role in the complex and contested situation in which people struggle for social justice.

A workshop participant commented:

Developing and using "power to" is about having a sense of the possible, having the imagination to see and do things differently - departing from the rules, working around the barriers, working with obstacles honestly and openly, and building alliances for change.

In a bureaucracy, such as a large aid organisation, whether government-affiliated or non-governmental, participants noted that this development of the imagination to see and do things differently is a challenge. Individual thought can be submerged, leading to "group think" where individuals remain closed minded, experience pressure towards uniformity, overestimate group power and consequently endorse self-censorship.

In our organisation there is a term for stepping out of "group think"; if you have a thought that is not along the railroad of thoughts, you must voice and use it carefully. Otherwise you might be carrying out a "career limiting move", more commonly referred to as a CLM. (Workshop participant)

Politicising development through rights-based approaches to development demands internal change within development agencies at both organisational and individual levels. However, actions that challenge existing power relations within and between development organisations and poor, marginalised and excluded groups carry risks with them. Above all, such actions reveal that development is a political as much as a technical process.

\subsection{Multiple worlds and accountabilities}

At the workshop, Rosalind Eyben outlined the multiple worlds that bilateral and multilateral donor organisations operate in, and the way this shapes its actors' accountability. Although these organisations' stated mandates are directed towards improving the lives of those living in poverty in recipient countries, in effect, primary lines of 
accountability for them is to the citizens of their donor countries: the taxpayers who support their governments. Systems, procedures, rules and relationships are designed around these accountability structures and are defined according to broader government interests and institutional culture. More recently, efforts to shift accountability towards host country governments are emerging. However, several questions remain. How effectively do recipient governments represent their citizens' voices? Should donors not be more directly accountable to host country citizens? And if so, how? (Eyben and Ferguson 2004).

Development organisations have different strengths and weaknesses in relation to the impact they might have on challenging power structures and facilitating the realisation of rights of those living in poverty. For instance, bilateral agencies, compared with international NGOs, may benefit from legitimacy they hold as representatives of foreign governments. However, their rights-based agenda may be constrained by their governments' political and diplomatic agendas. Being foreign also has its limitations and might potentially prevent donors from accessing networks and coalitions with whom they could work, as well as define the boundaries of the relationship with these actors.

NGOs are also constrained by the different dynamics and interests governing the worlds their offices operate in. They are in different positions and face different challenges and comparative advantages. They may have stronger local networks or histories of opposition to governments. However, being involved in legal and political rights issues can lead to clashes with governments. In one such case, cited by a participant, a host country government threatened to close down an international NGO's rights-based programme for fear that "foreign" lawyers would spread misinformation about government activities. Had it not been for other NGOs lobbying with them to prevent its closure, their work would have been stopped.

One of our proposals was funding an ecotourism initiative to be carried out by indigenous people. The recipient country's Ministry of Tourism said that indigenous groups had approved the proposal, but we discovered that an indigenous community was suing the government for expropriating their land. It was not clear how the indigenous communities would be compensated. The prominent view from within my organization was not to involve ourselves with internal politics and to assume that if the proposal was backed by the government, it was legitimate. I was personally concerned that we were funding something so contested by the rights-holders that the funds were meant to benefit. (Workshop participant)

\subsection{Power and knowledge}

Post-modernism has challenged the idea of objective value-free knowledge that is de-linked from power. Knowledge, i.e. how we understand and describe the world, is contingent on our time and place and the relations of power that shape our lives. For Foucault (Rabinow 1984), power and knowledge are inseparable. Power/knowledge works through discourses that frame what is thinkable and doable. Discourses are not only the way that things are said or written, but also concrete activities associated with them, such as LogFrames or Poverty Reduction Strategy Papers (PRSPs) in a development setting. Through deconstruction of these discourses, closely examining the concepts, practices, statements and beliefs associated with them, Foucault showed that the effects of power can be made visible. Thus, one step to changing power relations in the international aid system is to deconstruct the discourse to reveal it for what it is (Cornwall and Brock 2004).

Foucault's interest in what and how we know, is important for development practice. His discussion of historical amnesia (what is forgotten by those with the power to construct knowledge) is particularly relevant (Foucault 1980). Critics of "development" argue that we collectively suffer from this amnesia. Their critique is addressing the problem of the politics of knowledge. What are the power implications of most research in developing countries being funded by organisations such as our own?

At the workshop, participants considered how the construction of knowledge that guides development organisations' policies is highly politicised. Development research and resulting analytical approaches are funded by, and therefore substantially shaped by, donors. Their priorities therefore structure the creation of knowledge and lead to a predetermined conclusion (Chambers and Pettit 2004). Consequently, donor harmonisation with shared priorities may result in "group think" in the international aid system. In speaking to one 
another, donors hold up a mirror and see only their own reflection. Participants noted that this also occurs along disciplinary boundaries, where individuals might group themselves according to their academic training and experience and only validate their own kind of knowledge.

Workshop participants noted that within their organisations, "group think" to a rights-based approach were often influenced by people's academic background or discipline. Political scientists and economists in one organisation openly contested a more politicised rights-based approach, while many governance people focused on civil and political rights, and on formal notions of power. Some participants suggested that economists tended to focus on needs and the budgets pertaining to fulfilling these needs, without necessarily asking who should have a voice in designing budgets. Their needs-based approach tended to be technocratic and top down, lacking acceptance of the conflict and complexity that often emerges when citizens have a right to voice, and to engage in political processes that affects their lives. Governance specialists, on the other hand, also grappled with understanding the indivisibility of these civil and political rights from economic and social rights.

\section{Using rights to influence power}

At the workshop, Eyben noted that all those present, including the IDS staff, were people who had benefited enormously from existing unequal power relations in the world today. Thus development work is paradoxical and contradictory because we are working to change those very systems and structures from which we have personally benefited. Just as the discourse of rights can be an instrument for changing power relations for greater social justice, can we also use our own positional power to help others realise their rights?

Individuals construct and are constructed by the organisations they work in. Their behaviour and rationale are guided by existing incentive structures. It is clear that as agents of change, development actors must call on themselves to do much more, to learn how and to work towards improving the institutions in which we work. To do this we must question the deep structures, procedures, and values that may be inherited from earlier times, such as the colonial period in the case of the UK Department for International Development (DFID).

Questioning structures, values and procedures may be perilous for personal careers and the need to be careful and pragmatic was noted by several present. Nevertheless, despite the risks associated with pursuing rights-based approaches, participants persevered in their search for strategies to pursue these approaches. Towards the end of the workshop, specific strategies emerged on how to use a rightsbased approach to development to change power dynamics in participants' programmes and partnerships, as well as internally within their organisations and at a personal level. Most of these practical suggestions were rooted in participant experience and emerged from action group discussions. In each instance, participants reflected on their own behaviour and actions, conscious of their use of power:

In Brazil racism was openly denied. Our organisation's work reinforced black citizens' voices. Always ask yourself what you are maintaining or supporting in your way of working. (Workshop participant)

\subsection{Tactical entry points}

Changing power relationships requires identifying entry points and hooks that match the type of power the individual and organisation possess with the types of spaces and actors they aim to influence. It demands prioritising the entry points for action in terms of the realistic expectations for change in light of power relations.

It is difficult to get people to accept a rightsbased approach. I had to be very tactical, and let people discover for themselves how rights can help explain why democracy is close to failure ... (Workshop participant)

Assessing a situation and developing a strategy and language that frames a rights-based approach in a way that responds to the internal priorities and values of an individual or organisation, and is acceptable (or even exciting), can be an effective tool for generating alliances and creating change.

One workshop discussion group emphasised the importance of making space within their own organisations to discuss and share experiences of implementing a rights-based approach. Existing work may already use a rights-based approach implicitly, but encouraging the naming of that work as rights-based helps promote a rights-based 
approach within an organisation and wins easy allies. In another case, if security is becoming an important issue, then a rights-based approach can be incorporated by advocating "human security" that puts a human face on security issues. Careful use of language and recognising the value of incremental change was considered key and that where the term is threatening, it should be used with caution.

\subsection{Making, bending and reshaping the rules of the game}

Participants suggested that existing upward lines of accountability have implications on how to effectively implement a rights-based approach. The rights-based approach has the potential to employ human rights institutions as tools of accountability. Donor communities have explicitly committed themselves to support international human rights frameworks through their actions. However, while many governments have signed up to these - nonrepresentative governments included - most have not fully ratified these conventions. To what degree are covenants such as the Millennium Development Goals, to which all donor countries have committed themselves, a potential accountability hook for donors advocating a politicised rights way forward?

One key aspect of power is the ability to use knowledge to frame the possible, set rules and delimit what counts as knowledge and whose knowledge counts. Making, bending and reshaping the rules of the game is one way for individuals to bring about changes. Those who carry out the rules can also learn how to bend them and can use their discretion to do things differently. Over time, this can translate into different procedures or can feed struggles for formal procedural change.

One official in a broader chain of rules and procedures can make a big difference. Where are the entry points where catalytic powers can be mustered? (Naila Kabeer at the workshop)

\subsection{Using the international rights frameworks with caution}

The language of human rights is powerful in both positive and negative ways. In some contexts, it can limit perspectives and different possibilities. In other circumstances, it can serve to promote social justice.

International human rights frameworks can provide the basis for common action on rights, but they can also trigger political turmoil. One donor agency's experience of using an international human rights framework as a basis for empowering minorities highlighted the complexities of linking a rights-based approach to an international human rights framework. While it provided a basis for structuring people's rights into programmes that were designed to address the problem of excluded minorities, this approach also had negative political implications for those same minorities because they now became perceived as more of a threat. The translation of international legal frameworks into local contexts can either strengthen or undermine local work as political implications of rights-based work reveals the existence of hidden power and triggers a reaction from that power.

Our international NGO has been working to balance formalisation with different ways of working and kinds of experiences. Formalisation can smother innovations and it is important to allow flexibility for local contexts. How do we "let 1000 flowers bloom" but ensure that a rightsbased approach works? There is no Bible or howto manuals for rights based approaches. We need examples that balance praxis with implementation. (Workshop participant)

\subsection{Building strategic alliances and coalitions}

A participant explained how his organisation had worked under the assumption that the shift from authoritarian rule to democracy would invoke deepseated change in the aid recipient country concerned. However, over time he and his colleagues learnt that democracy did not necessarily create the space for political participation since the existing political structure was founded on corruption, mismanagement of resources and lack of transparency. Unless these rules were changed, democracy would remain rhetorical. An issue-based approach was employed to build up coalitions around these concerns that are beginning to address how power plays itself out in the short and in the long term. This approach also shifts away from stakeholder analysis that might pick up on divisions, and helps to identify identities around which people and organisations come together.

Coalitions with other actors is essential, given individuals' and their organisations' positional limitations. Within alliances, information sharing 


\section{Box 2: The Potential of Invited Spaces?}

She wanted to remember every detail of the building so that she could relay it all to her people. There was little time to experience the building, though. And as she entered deeper and deeper into the structure, past one security gate after another, she could feel her pace and heart rate begin to race.

Why were these officials asking her for all these documents at every doorway? Perhaps her hosts had forgotten to tell them that she had been invited to this place. Surely such a small person from such a simple and poor place could not be a threat to the sophisticated United Nations of New York City!

Exhausted and shaken, she was directed to a room at the end of another long corridor. It was only large wooden doors that separated her from those that had the power to end the terror her people were experiencing back home. Her trembling hand reached towards the door handle. A uniformed official blocked her arm brusquely. He asked for her identification and scrutinised it carefully. He told her she had five minutes. He opened the door and told her where to stand.

The big wooden doors closed behind her and she stared into an audience of important and powerful people. This was her chance. She was exhausted. Her legs trembled, her voice shook. She could not remember. Her time was up and the uniformed man escorted her out of the room.

Confusion consumed her. Why did the two important men sitting behind the gold signs: "USA" and "UK" not listen? What were they talking about between themselves that was so important? Perhaps they did not know that she had been invited to speak with them.

Source: Hughes et al. (2003).

is key both internally and externally. So is modesty, when calculating expectations of one another with respect to comparative advantage. True partnerships are based on transparent and full information sharing and mutual respect. When part of an alliance it is important not to hide when things go wrong.

For national level organisation alliances, it is important to foster linkages with local organisations that are already working on rights-based approaches. In many cases local-level NGOs may have been developing a rights-based approach and will have built strong alliances within communities around rights. In turn, these organisations may not be able to make themselves heard in other forums. Through a strategic alliance, local experiences can be heard in spaces that might otherwise be closed to them. These alliances could also help donor agencies and international NGOs to influence power dynamics that would otherwise be out of reach.

\subsection{Enabling the strengthening claimed and created spaces ${ }^{1}$}

Claimed and created spaces have the potential to shift power dynamics (Cornwall 2002), but supporting them to ensure that this is effective, is a challenge for many development actors. Power is contextual and people with it in created and claimed spaces, may not be confident or effective in invited spaces. Linking actors in claimed and created spaces to invited spaces is not necessarily easy and may require building the capacity to articulate and present oneself convincingly in an invited space, and exert "agency" in an effective manner, as for example in the drama of the civil society representative in the invited space of the United Nations (see Box 2).

Here, participants raised the question as to whether invited spaces should be modified for more effective and inclusive participation of those living in poverty and their representatives, or whether it is the participants who must learn the rules, norms and regulations that would make them more effective in these spaces.

\subsection{Building the capacity for agency}

Building the capacity of people living in poverty and in other marginalised and excluded groups to articulate their rights is a necessary element to using a rights-based approach that challenges power relationships. A rights-based approach requires that both the staff involved with implementation and the communities involved in rights-based work have an understanding of their mutual rights, and are able to articulate those rights in terms of their own experiences and contexts. Without this, it is difficult for any successful mobilisation around claiming 
rights to emerge. One participant offered the example of an international NGO working on health care at a local level. Members of the community believed they were powerless. The rights-based approach developed a sense of agency, and raised aspirations to make people believe that they could take on the system. Limitations at other levels emerged, however, highlighting the challenge of not raising false expectations through this approach.

\subsection{Providing evidence}

Documenting success stories of rights-based approaches and using strong and convincing evidence strategically can gain support within the organisation as well as more broadly. This material can be employed to challenge existing assumptions that are often bound by disciplinary biases, for example, the assumption that more hospitals will reduce child mortality versus the assertion that realising women's rights and empowerment will not. To do this effectively means that those situated in development organisations be prepared to empathise with the point of view of those in the organisation who are being targeted for influence.

We sit smug in our single-minded groups. We must face the discomfort of really listening to others to assess what we can learn from them, where they are coming from, and how we can influence them. (Workshop participant)

Rights-based approaches work very differently in different contexts and examples of how rights-based approaches have been implemented in particular contexts provide important lessons. It is principles, not checklists that define and underline the approach.

\section{Conclusion: walking the talk}

A combination of factors can make rights-based approaches dangerous to its advocates. Development organisations operate within multiple worlds. They selectively use and produce knowledge and perverted accountability and incentive systems seem to work in combination to constrain the political change that working for the rights of people living in poverty requires. Bureaucracy-driven "group think", discussed above and disciplinary turf wars can also contribute to institutional and individual paralysis. Similarly, programmes that explicitly work towards realising the rights of people living in poverty might be considered as threatening by governments or others.

The problem is not whether you are radical or not. It is about being more open and democratic in the way institutions make their decisions. How does one cut through that feeling of patronage and inequality? How does one move towards equal partnership with the poor? (Workshop participant)

Rights-based approaches to development inherently politicise development actors' work by challenging the power structures that not only define decision making at programme level, but also at internal, organisational and personal levels. The workshop came to many conclusions, but most obvious to all who participated was that the walls that such an approach will come up against run deep within institutional structures and the cultures, values and priorities that underpin them.

The participants reflected that essentially, accountability and responsibility must be brought into the development equation at all levels, drawing upon our own personal sense of citizenship and accountability to people living in poverty. There was a call to examine where we are within existing power matrices, to look at our individual behaviour and use our changing behaviour strategically to further accountable, transparent, democratic and honest decision making in our work and among our colleagues. In other words, we must apply the governance agenda to ourselves. 


\section{Notes}

* This article draws on a workshop on rights and power held at the Institute of Development Studies (IDS) on 23 November, for 27 representatives of bilateral and multilateral donors and international NGOs already actively engaged in the effort to "mainstream" rights in their organisation. This workshop, sponsored by the Development Research Centre on Citizenship, Participation and Accountability, was linked to the publication of IDS Policy Brief, 'The rise of rights' (Eyben 2003). The authors would like to acknowledge the efforts of the workshop participants to engage with some of the challenging issues raised in this article; their contributions have been invaluable. This article

\section{References}

Chambers, R. and Pettit, J., 2004, 'Shifting power to make a difference', in L. Groves and R. Hinton (eds), Inclusive Aid: Changing Power and Relationships in International Development, London: Earthscan

Chapman, J., 2002, System Failure: Why Governments Must Learn to Think Differently, London: Demos

Clegg, S.R., 1989, Frameworks of Power, London: Sage

Cornwall, A., 2002, 'Making spaces, changing places. Situating participation in development', IDS Working Paper 170, Brighton, Institute of Development Studies

Cornwall, A. and Brock, K., 2004, 'Beyond buzzwords: "poverty reduction", "participation" and "empowerment" in development policy', UNRISD Programme Paper, Geneva: United Nations Research Institute for Social Development

Cornwall, A. and Schattan de Coelho, V. (eds), 2004, 'New democratic spaces?', IDS Bulletin, Vol 35 No 2, Brighton: Institute of Development Studies

Eyben, R., 2003, 'The rise of rights: rights-based approaches to international development', IDS Policy Brief 17, Brighton: Institute of Development Studies

Eyben, R. and Ferguson, C., 2004, 'How can donors become more accountable to poor people?', in L. Groves, and R. Hinton (eds), Inclusive Aid: Changing Power and Relationships in International Development, London: Earthscan

Foucault, M., 1980, Knowledge/Power; Selected Interviews and Other Writings, New York: Pantheon Books

Gaventa, J., 1980, Power and Powerlessness; Quiescence and Rebellion in an Appalachian Valley, Urbana: University of Illinois Press

Gould, J. and Ojanen, J., 2003, 'Merging in the circle: the politics of Tanzanias's Poverty Reduction draws on the unpublished workshop report by Alexandra Hughes, Rosalind Eyben, Joanna Wheeler and Patta ScottVilliers (2003).

1. In this context, "spaces" refers to forums, arenas or other opportunities for engagement between state or other powerful institutions and civil society or citizen's groups (see Cornwall 2002; Cornwall and Schattan de Coelho 2004). Claimed space refers to spaces that have been created by the state, but have been taken up by civil society groups and used to articulate rights claims. "Created spaces" refers to spaces that have emerged in response to demands from social movements or other forms of struggle.

Strategy', Policy Papers 2, Helsinki: Institute of Development Studies

Groves, L. and Hinton, R. (eds), 2004, Inclusive Aid: Changing Power and Relationships in International Development, London: Earthscan

Hughes, A., Eyben, R., Wheeler, J. and Scott-Villiers, P., 2003, 'Rights and Power Workshop' Report, Development Research Centre on Citizenship, Participation and Accountability, unpublished manuscript, Brighton: Institute of Development Studies

Irvine, R., Chambers, R. and Eyben, R., 2004, 'Learning from poor people's lives', Lessons for Change 13, Brighton: Institute of Development Studies

Lukes, S., 1974, Power: A Radical View, London: Macmillan

Midgely, M., 1996, Utopias. Dolphins and Computers, London: Routledge

Pasteur, K. and Scott-Villiers, P., 2004, 'Minding the Gap Through Organisational Learning', in L. Groves and R. Hinton (eds), 2004, Inclusive Aid: Changing Power and Relationships in International Development, London: Earthscan

Rabinow, P. (ed.), 1984, The Foucault Reader, New York: Pantheon

Reason, P., 1998, 'A participatory worldview', Resurgence 168: 42-4, www.bath.ac.uk/ $\sim$ mnspwr/Papers/Participatoryworld.htm (accessed 18 August 2004)

Scott-Villiers, P., 2004, 'Personal change and responsible wellbeing', in L. Groves and R. Hinton (eds), Inclusive Aid: Changing Power and Relationships in International Development, London: Earthscan

VeneKlasen, L. and Miller, V., 2002, A New Weave of Power, People and Politics: The Action Guide for Advocacy Citizen Participation, Oklahoma City: World Neighbors 